\title{
ULTRASONOGRAPHY ACCURATELY EVALUATES THE DIMENSION AND SHAPE OF THE PILONIDAL SINUS
}

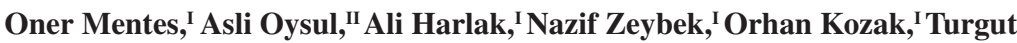 \\ Tufan ${ }^{\mathrm{I}}$
}

doi: $10.1590 / \mathrm{S1807-59322009000300007}$

Mentes O, Oysul A, Harlak A, Zeybek N, Kozak O, Tufan T. Ultrasonography accurately evaluates the dimension and shape of the pilonidal sinus. Clinics. 2009;64(3):189-192.

PURPOSE: To study the benefits of ultrasonography for detecting the borders of pilonidal sinus tissue. The correlation between physical and ultrasonographic examination was used for surgical planning.

METHOD: Between April and December 2004, 73 patients were recruited for this study. All patients were examined, and the borders of the sinus tissue were marked on the skin according to palpation before surgery. The surgeon also made a treatment plan considering the diseased tissue and marked a possible incision line. Patients were subsequently examined with ultrasonography. According to the ultrasonographic evaluation, the margins, extensions, and openings of pilonidal sinus tissue were determined and marked on the patient in a different color by a radiologist prior to surgery. The most suitable surgical treatment was decided according to the information obtained by ultrasonography.

RESULTS: The average age was $23.03 \pm 3.05$ (range 18-39) years. We found 81 lesions in 73 patients. Ultrasonographic borders of sinus tissue were similar to the borders marked by the surgeon in 56 patients $(76.7 \%)$. In the remaining 17 patients $(23.3 \%)$, ultrasonography detected branches or borders that distinctly exceeded the planned incision line. After ultrasonographic examination, the surgeon changed his incision line in 14 patients and the surgical intervention in 3 patients.

CONCLUSION: Palpation and methylene blue injection do not provide appropriate information in many patients. Our study revealed that pre-operative ultrasonography can improve the identification of the sinus tract and its branches when compared to palpation and methylene blue injection.

KEYWORDS: Pilonidal sinus; Ultrasonography; Surgical plan; Complication

\section{INTRODUCTION}

Pilonidal sinus disease (PSD) was first described by Mayo in 1833. As cited by Hull and $\mathrm{Wu},{ }^{1}$ Anderson described the treatment of the disease for the first time in 1847. Whether it is an acquired or congenital disease has confused physicians since its description, and today surgeons believe it is primarily the result of acquired conditions. ${ }^{2}$ PSD is

IDepartment of General Surgery, Gulhane Military Medical Academy Ankara, Turkey.

IIDepartment of Radiology, Etimesgut Military Hospital - Ankara, Turkey.

Tel. : +90.312.304 5015

Fax: +90.312.3045100

Email: onermentes@yahoo.com

Received for publication on July 13, 2008

Accepted for publication on November 13, 2008 a chronic, painful condition that typically occurs in the intergluteal region and is mainly observed in young adults. Numerous operative and conservative treatments have been described for the management of PSD; however, there is still debate on the ideal treatment. Chronic PSD is treated with a wide excision and primary closure or secondary healing. The surgeon needs to know the dimensions, location, borders, and branches of the pilonidal sinus cavity in order to plan the operative strategy. Ellipsoidal excision and primary closure are preferable treatments for small pilonidal sinuses. If the sinus tract is irregular or too large, however, alternative surgical approaches such as the Limberg flap or secondary healing may be needed.

Palpation and methylene blue injection are typically used to estimate the borders of diseased tissue; however, most operative findings do not mach the actual borders. To 
date, no clinical study has described the sinus tract using ultrasonography prior to surgery in PSD patients. The aim of this prospective study was to evaluate the borders, opening, and location of the sinus nest prior to surgery using ultrasonography.

\section{PATIENTS AND METHODS}

With institutional approval and written informed consent, this study included 73 patients who underwent surgery for PSD of the sacrococcygeal region. We carried out this prospective study at the Etimesgut Military Hospital, Ankara, Turkey from April 2004 to December 2004. The data obtained were age, gender, body mass index (BMI, $\mathrm{kg} / \mathrm{m}^{2}$ ), past history of drainage, type of disease (primary or recurrent), duration of the symptoms, and number of orifices. Patient characteristics are shown in table 1. The criterion for exclusion was acute infection of the disease. All patients were examined by the same surgeon, and the borders of the sinus tissue were marked on skin according to palpation prior to surgery. The surgeon also made a treatment plan considering the diseased tissue and marked a possible incision line. Patients were then examined using ultrasonography prior to surgery. Examinations were performed with the use of a $7.5-\mathrm{MHz}$ linear probe on a LOGIQ 5 pro ultrasound scanner (General Electric,
USA). According to the ultrasonographic evaluation, the margins, extensions, sinus tract, branches, and openings of the pilonidal sinus tissue were determined and marked on the patient in a different color. All scanning was performed by the same radiologist, and power Doppler mode was used when needed. The most suitable surgical treatment was decided for each patient according to the information obtained by the ultrasonography.

Results are expressed as the mean \pm standard deviation (SD) and percent. The differences between groups were tested for significance by an independent samples t-test. Statistical significance was defined as $P<0.05$.

\section{RESULTS}

All patients were males with an average age of $23.03 \pm$ 3.05 (range 18-36) years. The mean duration of symptoms was $23.21 \pm 18.95$ (range 2-120) months. Three patients (4.1\%) had recurrent disease and required one or more additional procedures.

The ultrasonographic borders of the sinus tissue were similar to the borders marked by the surgeon in 56 patients $(76.6 \%)$. In the remaining 17 patients (23.3\%), ultrasonography detected branches or borders that distinctly exceeded the planned incision line. The surgeon had to change the incision line in 14 patients and the

Table 1 - Patient characteristics

\begin{tabular}{|c|c|c|c|c|c|c|}
\hline Characteristics & $\begin{array}{l}\text { Number of openings } \\
\text { (with physical } \\
\text { examination) } \\
\text { (Mean } \pm \text { SD) }\end{array}$ & P Value & $\begin{array}{l}\text { Number of openings } \\
\text { (with USG) } \\
\text { (Mean } \pm \text { SD) }\end{array}$ & P Value & $\begin{array}{l}\text { Volume of lesion } \\
\qquad\left(\mathrm{mm}^{3}\right) \\
(\text { Mean } \pm \mathrm{SD})\end{array}$ & P Value \\
\hline Abscess drainage (once or more) & & 0.417 & & 0.813 & & 0.034 \\
\hline Yes $(n=10)$ & $2.4 \pm 0.69$ & & $1.3 \pm 0.94$ & & $2904.22 \pm 3505.36$ & \\
\hline No $(n=63)$ & $2.82 \pm 1.6$ & & $1.23 \pm 0.91$ & & $1439.67 \pm 1534.03$ & \\
\hline Duration of symptoms (month) & & 0.742 & & 0.283 & & 0.494 \\
\hline$\leq 12$ months $(\mathrm{n}=14)$ & $2.64 \pm 2.2$ & & $1.0 \pm 0.87$ & & $1859.01 \pm 2701.38$ & \\
\hline$>12$ months $(\mathrm{n}=59)$ & $2.79 \pm 1.3$ & & $1.29 \pm 0.91$ & & $1480.71 \pm 1642.05$ & \\
\hline Age & & 0.557 & & 0.381 & & 0.034 \\
\hline$\leq 25$ years old $(n=63)$ & $2.81 \pm 1.54$ & & $1.27 \pm 0.87$ & & $1788 \pm 2029.27$ & \\
\hline$>25$ years old $(n=10)$ & $2.5 \pm 1.35$ & & $1.0 \pm 1.15$ & & $617 \pm 497.720$ & \\
\hline Body mass index $\left(\mathrm{kg} / \mathrm{m}^{2}\right)$ & & 0.426 & & 0.982 & & 0.922 \\
\hline$\leq 25(\mathrm{n}=43)$ & $2.64 \pm 1.59$ & & $1.23 \pm 0.81$ & & $1613.41 \pm 1819.46$ & \\
\hline$>25(\mathrm{n}=30)$ & $2.93 \pm 1.41$ & & $1.24 \pm 0.98$ & & $1660.54 \pm 2118.83$ & \\
\hline Recurrence (after surgery) & & 0.658 & & 0,758 & & 0.924 \\
\hline Yes $(n=2)$ & $2.76 \pm 1.36$ & & $1.96 \pm 1.02$ & & $1788.93 \pm 1566.85$ & \\
\hline No $(n=71)$ & $2.80 \pm 1.49$ & & $1.37 \pm 0.87$ & & $1696 \pm 1829.27$ & \\
\hline
\end{tabular}

SD = Standard deviation; USG = Ultrasonography 
surgical approach in three patients after ultrasonographic examination. In these three patients, the surgical intervention was planned as an ellipsoidal excision and primary closure. After ultrasonographic examination, the surgeon decided to make a Limberg flap in two patients and to leave the sinus open for secondary healing in one patient because these patients had two or three lesions located outside the intergluteal line. In all patients, surgically excised tissue and shape was compatible with the borders marked by the ultrasound. Surgeons did not need to modify the incision during the operation. All lesions were found in the incision line, and ultrasonography revealed the entire sinus tract and its branches. We found 82 lesions in 73 patients. Sixty-five patients $(89.2 \%)$ had one lesion, seven patients $(9.5 \%)$ had two lesions, and one patient $(1.3 \%)$ had three lesions. In eight patients, the surgeon was unable to determine whether there was more than one sinus tissue. The average lesion volume was $1578.13 \pm 2003.85$ (range $25.5-10136.30$ ) $\mathrm{mm}^{3}$. Ultrasonography detected $1.24 \pm 0.91$ (range $0-4$ ) orifices that led to the pilonidal sinus tissue, and $2.76 \pm 1.51$ (range 1-7) orifices were found during physical examination. The mean BMI of the patients was $24.83 \pm 2.65$ (range 17.72$34.16) \mathrm{kg} / \mathrm{m}^{2}$. All patients were operated on under spinal anesthesia. We performed 56 (76.8\%) ellipsoidal excisions and primary sutures, 15 (20.5\%) Limberg flap procedures, and two $(2.7 \%)$ marsupializations. Wound infections developed in two patients (2.7\%), hematoma occurred in one patient $(1.3 \%)$, and there was no wound dehiscence after the removal of sutures in all patients. The rate of recurrence within a median 18-month follow-up was $2.7 \%$ of the cases.

\section{DISCUSSION}

Pilonidal sinus disease is a painful and chronic condition that occurs in the intergluteal region. ${ }^{1}$ Today, the acquired theory has gained general acceptance. Karydakis stated that three factors are required for hair penetration: the invader, consisting of loose hair, a force that causes hair insertion, and vulnerability of the skin to the insertion at the depth of the natal cleft. ${ }^{3}$ Pilonidal sinus disease can be diagnosed easily by surgeons; however, the main problem after surgery is recurrence. Excision of the nest continues to be the most widely practiced surgical technique for treating PSD. Various operations have been described for the excision of lesions.

Surgical treatment was previously derived from the prevalent pathogenesis theory. When the congenital theory was accepted, the recommended treatment was the excision of the cysts and surrounding tissue to the postsacral fasia in an attempt to eliminate all congenital islands of the epithelium. Since the theory of acquired disease has prevailed, however, dissection has been limited to the pilonidal cyst/sinus itself and the immediate surrounding inflammatory tissue and does not routinely include excision of the deeper layers. ${ }^{4}$

Various surgical methods have been used to treat PSD, the most common of which is excision and primary closure for small lesions. For larger and multiple sinuses, however, the wound is left open to be closed by a secondary repair or flap rotation after excision of the lesions. Several techniques have been used to cover the defect after radical excision. These are primary closure, Z-plasty, W-plasty, $\mathrm{V}-\mathrm{Y}$ fasciocutaneous flap, rhomboid flap (Dufourmentel or Limberg flap), and a gluteus maximus rotational flap. ${ }^{5-8}$

The aim of the surgery is to remove all the sinus tissue. Leaving hair containing tracts without excision may be one cause of recurrent disease. Some surgeons therefore dye the nest with methylene blue intra-operatively to completely visualize tracts for subsequent curative excision. In some cases, sinus nests can rupture, and methylene blue can spread into the operation field and prevent the visualization of the pilonidal sinus tissue. Healthy tissue can also be stained, thereby leading to larger excisions.

Before surgery, the surgeon chooses the operation type according to the location of the openings, extension of the lesion, and depth of the natal cleft. In particular, the type of flap should be drawn on the skin before the procedure. If the diseased tissue extends into unexpected areas, the surgeon should not modify the skin incision shape during flap surgery. For this reason, accurately determining the diseased tissue border before surgery is essential.

The number of openings was not detected as well by ultrasonography compared to macroscopic examination of the surgical specimen. This lack indicates that not all openings reached the diseased tissue (i.e., the methylene blue injection was unable to fill the entire lesion). Palpation does not yield enough information to determine the borders of the diseased tissue. In our study, one patient had three lesions, and seven patients had two lesions. There was no bridge between the lesions. Ultrasonography helped to change the surgical plan in 17 patients.

Surgical success depends on the resection of all diseased tissue. The location and dimension of lesions could play an important role in deciding surgical intervention. Today, many surgeons use methylene blue injection or palpation to identify the margins of the diseased tissue. In our cohort, these methods were unable to identify the borders of diseased tissue in all patients. The diseased tissue should be placed in the excised area, especially in flap surgery, because of the difficulty in modifying the incision line during surgery.

In our study, we found that the pilonidal sinus tract and its branches could be accurately identified using 
ultrasonography. The surgeons who took part in this study determined the surgical plan according to the localization of the diseased tissue based on the ultrasonography findings. All lesions were placed in the marked area, especially in flap operations.

\section{CONCLUSION}

This study showed that the sinus tract, branches, and borders could be accurately identified by ultrasonography and that this method can be employed while deciding upon a surgical intervention for pilonidal sinus patients.

\section{REFERENCES}

1. Hull TC, Wu J. Pilonidal disease. Surg Clin N Am 2002;82:1169-85.

2. da Silva JH. Pilonidal cyst: cause and treatment. Dis Colon Rectum. 2000; 43:1146-56.

3. Karydakis GE. Easy and successful treatment of pilonidal sinus after explanation of its causative process. ANZ J Surg. 1992;62:385-9.

4. Spivak H, Brooks VL, Nussbaum M, Friedman I. Treatment of Chronic Pilonidal Disease. Dis Colon Rectum. 1996; 39:1136-39.

5. Manterola C, Barroso M, Araya JC, Fonseca L. Pilonidal disease: 25 cases treated by the Dufourmentel technique. 1991; 34:649-52.
6. Khatri VP, Espinosa MH, Amin AK. Management of recurrent pilonidal sinus by simple V-Y fasciocutaneus flap. Dis Colon Rectum. 1994; 37:1232-5.

7. Ozgültekin R, Ersan Y, Ozcan M, Ozçelik F, Celik V, Cerçel A, et al. Die Therapie des sinus pilonidalis mit dem Transpositionslappen nach Limberg. Chirurg. 1995; 66:192-5.

8. Bose B, Candy J. Radical cure of pilonidal sinus by Z plasty. Am J Surg. 1970; 120:783-6. 